\title{
La contratación de los servicios jurídicos en la ley 9/2017, de 8 de noviembre, de Contratos del Sector Público ${ }^{1}$
}

\section{The contracting of legal services under law 9/2017, november 8th, on public sector contracts}

\author{
Jesús Rubio Beltrán \\ Diputación Provincial de Zaragoza (España) \\ jrubiobeltran@gmail.com
}

\begin{abstract}
NOTA BIOGRÁFICA
Licenciado en Derecho por la Universidad de Zaragoza. Funcionario de Administración Local (Técnico de Administración General, Rama Jurídica), con una trayectoria profesional de más de 18 años en el ámbito local, y habiendo desempeñado diferentes puestos de trabajo en entidades locales de la provincia de Zaragoza, a los que se atribuye el asesoramiento legal preceptivo, y también el control y fiscalización interna de la gestión económico-financiera y presupuestaria, en particular en el sector de la contratación pública. Master en Contratación Pública Local por el Instituto de Derecho Local de la Universidad Autónoma de Madrid.
\end{abstract}

\section{RESUMEN}

La Directiva 2014/24/UE, aprobada por el Parlamento Europeo el 14 de enero de 2014 y publicada en el Diario Oficial de la Unión Europea el 28 de marzo de 2014, incorpora novedades en cuanto al régimen jurídico de los contratos de servicios en general, y también en cuanto al régimen aplicable a los contratos de servicios jurídicos, en particular. Transpuesta la Directiva por la Ley 9/2017, de 8 de noviembre, de Contratos del Sector Público, las exclusiones de los servicios jurídicos de su regulación y aplicación, lejos de ser respetadas, no han sido atendidas por el legislador nacional, ni tan siquiera en la regulación de un régimen simplificado de contratación de estos servicios. Este estudio aborda el tratamiento de la contratación de los servicios jurídicos en la LCSP; las particularidades en la contratación de estos servicios derivadas de la mutua confianza como elemento que caracteriza la prestación de los servicios jurídicos; y la necesidad de un tratamiento diferenciado en la contratación de determinados servicios jurídicos -los excluidos por el art. 10.d) de la Directiva-, como medida posible en aplicación de la Directiva 2014/24/UE².

1 Trabajo Fin de Máster presentado en la Sexta Edición del Máster de Contratación Pública Local de la Universidad Autónoma de Madrid, bajo la dirección académica de la Profesora de Derecho Administrativo de la Universidad Autónoma de Madrid Silvia Díez Sastre, Madrid, junio 2018.

2 Abreviaturas, siglas y acrónimos utilizados: CE: Constitución Española de 1978; DA: Disposición adicional; ICAL: Orden HAP/1781/2013, de 20 de septiembre, por la que se aprueba la Instrucción del modelo normal de contabilidad local; IVA: Impuesto sobre el Valor Añadido; JCCA: Junta Consultiva de Contratación Administrativa del Estado; JCCA Ar: Junta Consultiva de Contratación Administrativa de la Comunidad Autónoma de Aragón; JCCA Cat: Junta Consultiva de Contratación Administrativa de la Comunidad Autónoma de Cataluña; art:: artículo; LOPJ: Ley Orgánica 6/1985, de 1 de julio, del Poder Judicial; LPAC: Ley 39/2015, de 1 de octubre, del Procedimiento Administrativo Común de las Administraciones Públicas; LRJSP: Ley 40/2015, de 1 de octubre, del Régimen Jurídico del Sector Público; LBRL: Ley 7/1985, de 2 de abril, reguladora de las Bases del Régimen Local; LALA, Ley 7/1999, de 9 de abril, de Administración Local de Aragón; TRRL: Real Decreto Legislativo 781/1986, de 18 de abril, por el que se aprueba el texto refundido de las Disposiciones Legales Vigentes en materia de Régimen Local; TRLRHL: Real Decreto Legislativo 2/2004, de 5 de marzo, por el que se aprueba el texto refundido de la Ley Reguladora de las Haciendas Locales; LCAP: Ley 13/1995, de 18 de mayo, de Contratos de las Administraciones Públicas; TRLCSP: Real Decreto Legislativo 3/2011, de 14 de noviembre, por el que se aprueba el texto refundido de la Ley de Contratos del Sector Público; LCSP: Ley 9/2017, de 8 de noviembre, de Contratos del Sector Público, por la que se 
REALA. Nueva Época - N. 11, Abril-Septiembre 2019 - ISSN: 1989-8975 - DOI: 10.24965/reala.v0i11.10570 - [Págs. 184-203]

La contratación de los servicios jurídicos en la ley 9/2017, de 8 de noviembre, de contratos del sector público

Jesús Rubio Beltrán

\title{
PALABRAS CLAVE
}

Contratos públicos; servicios jurídicos; calificación del contrato; transposición de Directivas.

\begin{abstract}
Directive 2014/24/EU, passed by the European Parliament on January 14th 2014 and published in the Official Journal of the European Union on March 28th 2014, throws new light on the legal regime of general service contracts, and particularly on the regime applicable to contracts of legal services. Once the Directive has been transposed into Law 9/2017 of November 8th on Public Sector Contracts, the exclusions of legal services from their regulation and application, far from being respected, have not been addressed by the national legislator, nor even in the regulation of a simplified system for contracting these services. This paper addresses the treatment of contracting legal services under the Public Contracts Law, the pecularities of the contract of these services based on mutual trust as an element that distinguishes the provision of legal services, and the need for differentiated treatment when contracting certain legal tools -those excluded by art. 10.d) of the Directive-, as a possible measure in application of Directive 2014/24/EU.
\end{abstract}

\section{KEYWORDS}

Public contracts; legal services; qualification of the contract; transposition of Directives.

\begin{abstract}
SUMARIO
INTRODUCCIÓN. LOS SERVICIOS JURÍDICOS COMO PRESTACIÓN DE LOS CONTRATOS PÚBLICOS. 2.1. LOS SERVICIOS JURÍDICOS EN LA DIRECTIVA 2014/24/UE. 2.2. LA REGULACIÓN DE LOS SERVICIOS JURÍDICOS EN LA LCSP. 2.3. EL TRATAMIENTO DE LOS SERVICIOS JURÍDICOS EN OTROS PAIISES DE LA UE. ALGUNOS ELEMENTOS DIFERENCIADORES EN LA CONFIGURACIÓN DEL CONTRATO DE SERVICIOS JURÍDICOS. 3.1. EL OBJETO DEL CONTRATO DE SERVICIOS JURÍDICOS. 3.2. EL PRECIO EN EL CONTRATO DE SERVICIOS JURÍDICOS. 3.3. LAS EXIGENCIAS DE SOLVENCIA EN EL CONTRATO DE SERVICIOS JURÍDICOS. 3.4. LA EXPERIENCIA COMO CRITERIO DE ADJUDICACIÓN EN EL CONTRATO DE SERVICIOS JURÍDICOS. 3.5. LA DURACIÓN DEL CONTRATO DE SERVICIOS JURÍDICOS. 3.6. LOS PROCEDIMIENTOS DE LICITACIÓN Y ADJUDICACIÓN DEL CONTRATO. LA NECESIDAD DE UN TRATAMIENTO DIFERENCIADO EN LA REGULACIÓN DE LOS SERVICIOS JURÍDICOS. 4.1. EL TRATAMIENTO DIFERENCIADO DE ALGUNOS SERVICIOS EN LA LCSP: LOS DENOMINADOS «SERVICIOS INTELECTUALES». 4.2. EL ELEMENTO FORMAL DEL CONTRATO DE SERVICIOS JURÍDICOS: LA VOLUNTAD DE LAS PARTES Y LA MUTUA CONFIANZA. CONCLUSIONES FINALES. BIBLIOGRAFÍA.
\end{abstract}

\section{INTRODUCCIÓN}

La Directiva 2014/24/UE ha modificado sustancialmente el régimen jurídico de la regulación de los servicios, eliminado su división en categorías y la aplicación de regímenes jurídicos diferenciados en atención a esa división. En lo que se refiere a la regulación de los servicios jurídicos, la Directiva establecía que estos servicios solamente quedaran sujetos a la normativa contractual pública cuando su presupuesto superara

\footnotetext{
transponen al ordenamiento jurídico español las Directivas del Parlamento Europeo y del Consejo 2014/23/UE y 2014/24/UE, de 26 de febrero de 2014.; LGP: Ley 47/2003, de 26 de noviembre, General Presupuestaria; LTBG: Ley 19/2013, de 9 de diciembre, de Transparencia, Acceso a la Información Pública y Buen Gobierno; LTPA: Ley 8/2015, de 25 marzo, de Transparencia de la Actividad Pública y Participación Ciudadana de Aragón; RD: Real decreto; RGLCAP: Real Decreto 1098/2001, de 12 de octubre, por el que se aprueba el Reglamento General de la Ley de Contratos de las Administraciones Públicas; ROF: Real Decreto 2568/1986, de 28 de noviembre, por el que se aprueba el Reglamento de Organización, Funcionamiento y Régimen Jurídico de las Entidades Locales; RPEL: Real Decreto 500/1990, de 20 de abril por el que se desarrolla el capítulo primero del título sexto de la Ley 39/1988, de 28 de diciembre, reguladora de las Haciendas Locales, en materia de presupuestos; RFALHN: Real Decreto 128/2018, de 16 de marzo, por el que se regula el régimen jurídico de los funcionarios de Administración Local con habilitación de carácter nacional); EAB: Real Decreto 658/2001, de 22 de junio, por el que se aprueba el Estatuto General de la Abogacía Española; CDEO: Código Deontológico Abogacía adaptado al Estatuto General de la Abogacía Española, aprobado por Real Decreto 658/2001, de 22 de junio, aprobado en el Pleno de 27 de septiembre de 2002 y modificado en el Pleno de 10 de diciembre de 2002; STS: Sentencia Tribunal Supremo; STC: Sentencia del Tribunal Constitucional; STSJ: Sentencia del Tribunal Superior de Justicia; TACPA: Tribunal Administrativo de Contratos Públicos de Aragón; TACRC: Tribunal Administrativo Central de Recursos Contractuales; TC: Tribunal Constitucional.
} 
REALA. Nueva Época - N. 11, Abril-Septiembre 2019 - ISSN: 1989-8975 - DOI: 10.24965/reala.v0i11.10570 - [Págs. 184-203]

los 750.000 euros (art. 4 de la Directiva), y que su objeto contractual no hubiera sido excluido expresamente al amparo de los artículos 7 a 17 de la misma ${ }^{3}$.

Una de las novedades que introduce la Directiva 2014/24/UE ${ }^{4}$ es, precisamente, la exclusión de su ámbito de aplicación de determinados servicios jurídicos. En concreto, el art. 10.d) de la Directiva, que regula determinadas "exclusiones específicas relativas a los contratos de servicios», dispone la inaplicación de la misma a aquellos contratos públicos de servicios que tengan como objeto:

«d) cualquiera de los siguientes servicios jurídicos:

i) representación legal de un cliente por un abogado, en el sentido del artículo 1 de la Directiva 77/249/CEE del Consejo (Considerando 25) en:

- un arbitraje o una conciliación celebrada en un Estado miembro, un tercer país o ante una instancia internacional de conciliación o arbitraje, o

- un procedimiento judicial ante los órganos jurisdiccionales o las autoridades públicas de un Estado miembro, un tercer país o ante órganos jurisdiccionales o instituciones internacionales.

ii) asesoramiento jurídico prestado como preparación de uno de los procedimientos mencionados en el inciso i) de la presente letra, o cuando haya una indicación concreta y una alta probabilidad de que el asunto sobre el que se asesora será objeto de dichos procedimientos, siempre que el asesoramiento lo preste un abogado en el sentido del artículo 1 de la Directiva 77/249/CEE.

iii) servicios de certificación y autenticación de documentos que deban ser prestados por un notario.

iv) servicios jurídicos prestados por administradores, tutores $u$ otros servicios jurídicos cuyos proveedores sean designados por un órgano jurisdiccional en el Estado miembro en cuestión o designados por ley para desempeñar funciones específicas bajo la supervisión de dichos órganos jurisdiccionales.

v) otros servicios jurídicos que en el Estado miembro de que se trate estén relacionados, incluso de forma ocasional, con el ejercicio del poder público.».

En el ámbito de la contratación pública los servicios jurídicos constituyen uno de los contratos típicos del sector público. Se recogen expresamente tanto en el Anexo XIV de la Directiva 2014/24/UE del Parlamento Europeo y del Consejo de 26 de febrero de 2014, como en el Anexo II del hasta hace poco vigente Real Decreto Legislativo 3/2011, de 14 de noviembre, por el que se aprueba el texto refundido de la Ley de Contratos del Sector Público (en adelante, TRLCSP) dentro de la categoría 21. Y, actualmente, figuran como uno de los considerados como servicios específicos o especiales relacionados en el Anexo IV de la LCSP.

Dentro de esta categoría se incluyen una relación de servicios de muy diferente naturaleza y que el vocabulario común de contratos (CPV) aprobado por el Reglamento Núm. 213/2008, de la Comisión, de 28 de noviembre de 2007, califica en tres grandes subcategorías que encuadra en los códigos 79110000-8 a 79140000-7: Representación en juicio; Asesoría; y Documentación e información jurídicas.

La propia Directiva de contratación pública los define con más precisión y restringe los servicios jurídicos, concretamente los dos primeros (servicios de representación en juicio y asesoría) a los definidos en el art. 1 de la Directiva 77/249/CEE, del Consejo, de 22 de marzo de 1977, que son las actividades de abogacía ejercidas en concepto de prestación de servicios. Y, a su vez, excluye estos servicios jurídicos de la aplicación de la Directiva (art. 10.d).

Por tanto, los servicios jurídicos de asesoría y representación en juicio en el ámbito de la contratación pública se refieren exclusivamente a los servicios prestados por abogados en cualquier ámbito o especialidad del derecho.

Los servicios prestados por abogados están regulados en España en el Real Decreto 658/2001, de 22 de junio, por el que se aprueba el Estatuto General de la Abogacía Española. El 31 de mayo de 2001 se

\footnotetext{
3 MORENO JUNCEDA, J. (abogado) (2017): “¿Por qué los servicios jurídicos no están excluidos de la Ley de Contratos Públicos?" (31 de octubre de 2017). Confilegal. https://confilegal.com/20171031-por-que-los-servicios-juridicos-no-estan-excluidos-de-la-leyde-contratos-publicos/ (consultado: 15-06-2018).

${ }^{4}$ Informe 14/2016, de 20 de julio, de la Junta Consultiva Contratación Administrativa de Aragón.
} 
REALA. Nueva Época - N. 11, Abril-Septiembre 2019 - ISSN: 1989-8975 - DOI: 10.24965/reala.v0i11.10570 - [Págs. 184-203]

suscribió el Pacto de Estado para la reforma de la justicia con el fin de abordar una modernización íntegra de nuestro sistema judicial, impulsando un nuevo modelo de justicia global y estable que garantice con rapidez, eficacia y calidad los derechos de los ciudadanos. Los abogados deben jugar en este proceso un papel esencial. En este sentido, el punto veinte del Pacto de Estado, relativo a los abogados, prevé de manera explícita la aprobación de un nuevo Estatuto de la Abogacía que constituya un nuevo marco normativo para el ejercicio de la profesión.

Para alcanzar una justicia más ágil y eficaz resulta fundamental modernizar la regulación de la profesión de abogado como colaborador necesario de la función jurisdiccional. El papel que desempeña el abogado en el ejercicio de su profesión y en defensa de su cliente contribuye activamente a mejorar e incrementar la calidad de la Justicia.

El art. 1 EAB establece que la abogacía es una profesión libre e independiente que presta un servicio a la sociedad en interés público y que se ejerce en régimen de libre y leal competencia, por medio del consejo y la defensa de derechos e intereses públicos o privados, mediante la aplicación de la ciencia y la técnica jurídicas, en orden a la concordia, a la efectividad de los derechos y libertades fundamentales y a la justicia.

En el ejercicio profesional, el abogado queda sometido a la normativa legal y estatutaria, al fiel cumplimiento de las normas y usos de la deontología profesional de la abogacía y al consiguiente régimen disciplinario colegial.

Es sobre esta categoría de servicios jurídicos -de representación en juicio y asesoría, y el resto de servicios que enumera el art. 10.b) de la Directiva 2014/24/UE-, incorporados por el legislador nacional en el art. 19.2.e) LCSP para ser excluidos de la regulación armonizada cualquiera que sea su importe, pero no de la aplicación de la LCSP, y no sobre el resto de servicios jurídicos, sobre la que se demanda la necesidad de un tratamiento diferenciado para su contratación por el sector público o bien su exclusión del ámbito de aplicación de la LCSP.

En este contexto, este trabajo aborda el tratamiento de la contratación de los servicios jurídicos en la LCSP. El estudio a realizar parte del análisis de los diferentes elementos que conforman este contrato de servicios: el objeto, el precio, la voluntad de las partes y la duración del contrato. En particular, y como elemento fundamental, se analiza el elemento subjetivo de la mutua confianza en la prestación de los servicios jurídicos. Este análisis concluirá, de ser posible, en la caracterización del contrato de servicios jurídicos como un contrato con características intrínsecas especiales.

Posteriormente, se hará una aproximación a las actuaciones relativas a la contratación de los servicios jurídicos en el sector público: la preparación del contrato, los procedimientos de licitación, la adjudicación y la formalización del contrato; analizando, respecto a estas cuestiones procedimentales, las dificultades y peculiaridades que surgen al aplicar las previsiones contenidas en la LCSP a este específico tipo de servicios. Con el análisis de las actuaciones preparatorias del contrato, se tratará también de concluir, de ser posible, la necesidad de exigir un tratamiento diferenciado en la contratación de los servicios jurídicos por el sector público.

Y, por último, se acometerá el estudio del tratamiento especial que la LCSP realiza de algunos servicios: los denominados «servicios intelectuales». Y la posibilidad de que los servicios jurídicos, con tal consideración, gocen también de un tratamiento diferenciado en la LCSP o bien, como posibilita la Directiva 2014/24/ UE, sean excluidos de su ámbito de aplicación, exclusión de la que existen modelos de los que tomar ejemplo en el Derecho comparado europeo.

\section{LOS SERVICIOS JURÍDICOS COMO PRESTACIÓN DE LOS CONTRATOS PÚBLICOS}

\subsection{Los servicios jurídicos en la Directiva 2014/24/UE}

La Directiva 2014/24/UE incorpora novedades en cuanto al régimen de los contratos de servicios en general, y también en cuanto al régimen aplicable a los contratos de servicios jurídicos, en particular.

Así, en relación con los contratos de servicios, desaparece su clasificación en 27 categorías, y con ello la dualidad de regímenes jurídicos en función de que el contrato lo fuera de las categorías 1 a 16 ó 17 a 27. De ello cabe deducir, en primer lugar, que la categoría de "contrato de servicios sujeto a regulación armonizada» a la que se refería el art. 16 TRLCSP queda uniformizada desde el punto de vista objetivo, subsistiendo alguna diferencia si atendemos al umbral económico del contrato, como más adelante se indicará. Hasta ahora sólo estaban sujetos a regulación armonizada los contratos de servicios comprendidos en las catego- 
REALA. Nueva Época - N.o 11, Abril-Septiembre 2019 - ISSN: 1989-8975 - DOI: 10.24965/reala.v0i11.10570 - [Págs. 184-203]

rías 1 a 16 del Anexo II del TRCLSP que superasen un determinado umbral económico, pero en ningún caso los de las categorías 17 a 27 , estando los contratos de servicios jurídicos comprendidos en la categoría 21.

Al analizar el régimen particular de los contratos de servicios jurídicos previsto en la Directiva es donde apreciamos novedades importantes. Y es que este tipo de contratos únicamente quedarán sujetos a la Directiva cuando concurran dos condiciones. La primera, que el importe del contrato supere los umbrales económicos fijados en el art. 4 de la Directiva 2014/24/UE. Y la segunda, que el objeto del contrato no haya sido objeto de una exclusión expresa conforme a lo dispuesto en los artículos 7 a 17 de la citada Directiva.

En este sentido, el art. 4 de la Directiva sitúa en 750.000 euros el umbral económico de sometimiento a las disposiciones de la Directiva para los servicios sociales y los servicios específicos recogidos en el Anexo XIV, entre los que se encuentran los contratos de servicios jurídicos en la medida en que no estén excluidos en virtud del art. 10.d), y de 135.000 o 209.000 euros, en el resto de contratos de servicios, en función del poder adjudicador del que se trate.

Y una de las novedades que introduce la Directiva 2014/24/UE es, precisamente, la exclusión de su ámbito de aplicación de determinados servicios jurídicos. En concreto, los referidos en el art. 10.d) de la Directiva.

La Directiva 77/249/CEE del Consejo, de 22 de marzo de 1977, a la que se refiere la Directiva 2014/24/ UE, está dirigida a facilitar el ejercicio efectivo de la libre prestación de servicios por los abogados. Y por ello el Considerando 25 de la Directiva 2014/24/UE, justifica la exclusión a la que se refiere el art. 10.d) en los siguientes términos: "Determinados servicios jurídicos son facilitados por proveedores de servicios nombrados por un tribunal o un órgano jurisdiccional de un Estado miembro, implican la representación de clientes en un proceso judicial por abogados, deben ser prestados por notarios o guardar relación con el ejercicio de una autoridad oficial. Dichos servicios jurídicos son prestados normalmente por organismos o personas nombrados o seleccionados mediante un procedimiento que no puede regirse por las normas de adjudicación de los contratos, como ocurre, por ejemplo, en algunos Estados miembros, con el nombramiento del ministerio fiscal. Por consiguiente, estos servicios jurídicos deben quedar excluidos del ámbito de aplicación de la presente Directiva».

Con independencia del carácter claro y preciso de la exclusión de los servicios jurídicos a través de abogado contenida en esta Directiva -lo que habría de haber supuesto su efecto directo desde el 18 de abril de 2016 mientras no se promulgara la nueva Ley-, la doctrina consultiva ${ }^{5}$ vino recordando, al igual que los Tribunales Administrativos Públicos de Contratos, entre ellos el de Aragón ${ }^{6}$, que dicho efecto directo requiere de la transposición formal al derecho interno, en especial cuando se trata del llamado efecto vertical descendente, por lo que habría que esperar a que la citada exclusión fuera transpuesta al derecho español para que fuera efectiva.

Sobre la aplicación directa del art. 10 de la Directiva, hay que recordar lo ya señalado con carácter general para cualquier precepto del que se predique su efecto directo ${ }^{7}$ : su contenido debe ser claro, preciso e incondicionado, es decir, que no requiera previamente de ningún acto de concreción para ser aplicado, tal y como se explica, entre otros, en el Informe 17/2015, de 3 de diciembre, de la JCCAAr. En este sentido, el art. 10.d) de la Directiva 2014/24/UE puede considerarse un precepto claro y preciso respecto de la exclusión del ámbito de la regulación de la Directiva de los trabajos de servicios jurídicos de defensa mediante abogado, por lo que cumpliría con tales requisitos para su aplicación directa.

Sin embargo, dado que conforme a la jurisprudencia del TJUE existe prohibición del efecto directo vertical descendente, los poderes adjudicadores no pueden ampararse en una norma de la Directiva no transpuesta, en perjuicio de los particulares o alterar su propio estatus jurídico. De esta forma, en tanto la mencionada exclusión no sea incorporada a nuestro ordenamiento jurídico, por transposición expresa de la Directiva por el legislador nacional, no puede invocarse su aplicación ${ }^{8}$.

Por otra parte, en cuanto a los contratos de servicios jurídicos no excluidos del ámbito de aplicación de la Directiva, por no tener encaje en ninguno de los supuestos señalados en el art. 10.d), habría que distinguir aquellos mencionados en el Anexo XIV de la Directiva (Códigos CPV 79100000-5 a 79140000-7), al que remite el art. 74 de la misma, para los cuales está prevista la aplicación de un régimen «simplificado» (según indica el Considerando 116 de la Directiva) definido en el Capítulo I del Título III de la Directiva 2014/24/UE.

\footnotetext{
5 Documento de Estudio de los Tribunales Administrativos de Contratación Pública, presentado y aprobado el 1 de marzo de 2016.

${ }^{6}$ Acuerdo 53/2016, de 31 de mayo, del Tribunal Administrativo de Contratos Públicos de Aragón.

7 Informe 14/2016, de 20 de julio, de la Junta Consultiva Contratación Administrativa de Aragón.

8 Acuerdo 53/2016, de 31 de mayo, del Tribunal Administrativo de Contratos Públicos de Aragón.
} 
REALA. Nueva Época - N.o 11, Abril-Septiembre 2019 - ISSN: 1989-8975 - DOI: 10.24965/reala.v0i11.10570 - [Págs. 184-203]

No obstante, los artículos 74 y siguientes de la Directiva no resultan de aplicación directa, por lo que resulta precisa también su transposición al Derecho nacional. Para el resto de contratos de servicios jurídicos -no excluidos ni sometidos al régimen de los artículos 74 y siguientes-, resultará de aplicación el régimen general previsto para los contratos de servicios.

La referencia que se hace al CPV 75231100-5 en el Anexo XIV, y que se ha incorporado en el Anexo IV de la LCSP, debe entenderse como un error pues no se recoge en el Reglamento (CE) 213/2008 de la Comisión de 28 de noviembre de 2007, que modifica el Reglamento (CE) 2195/2002 del Parlamento Europeo y del Consejo, por el que se aprueba el Vocabulario común de contratos públicos (CPV), y las Directivas 2004/17/CE y 2004/18/CE del Parlamento Europeo y del Consejo sobre los procedimientos de los contratos públicos, en lo referente a la revisión del CPV ${ }^{9}$.

De especial interés para los abogados y para los organismos y las empresas del sector público que contratan los servicios de estos profesionales puede resultar el nuevo tratamiento de la contratación pública de algunos servicios jurídicos y las posibilidades en su prestación que se generaría, bien de regularse un procedimiento especial para la contratación de estos servicios o bien de aplicar la exclusión prevista en la Directiva.

\subsection{La regulación de los servicios jurídicos en la LCSP}

Los servicios jurídicos prestados al sector público no tienen una regulación específica en la LCSP equiparándose al resto de servicios, igual que ocurría con la regulación del TRLCSP, a salvo de la exclusión de la regulación armonizada de determinados servicios jurídicos, y algunas cuestiones procedimentales de poca o escasa relevancia.

El art. 17 LCSP define el contrato de servicios en los siguientes términos: "Son contratos de servicios aquellos cuyo objeto son prestaciones de hacer consistentes en el desarrollo de una actividad o dirigidas a la obtención de un resultado distinto de una obra o suministro, incluyendo aquellos en que el adjudicatario se obligue a ejecutar el servicio de forma sucesiva y por precio unitario. No podrán ser objeto de estos contratos los servicios que impliquen ejercicio de la autoridad inherente a los poderes públicos».

Y el art. 11.2 y 3 LCSP, con la denominación "Otros negocios y contratos excluidos», excluye del ámbito de aplicación de la norma, únicamente, y a diferencia de la regulación contenida en la Directiva 2014/24/ UE, los siguientes servicios jurídicos: a) Las relaciones jurídicas consistentes en la prestación de un servicio público cuya utilización por los usuarios requiera el abono de una tarifa, tasa o precio público de aplicación general, es decir, los servicios jurídicos sometidos a arancel, y b) Los contratos relativos a servicios de arbitraje y conciliación.

Quedan de este modo incorporados y sometidos a las previsiones de la LCSP, de forma casi incomprensible, los servicios jurídicos que la Directiva 2014/24/UE excluía de forma expresa en el art. 10.d).

Únicamente, la LCSP, al regular los contratos sujetos a regulación armonizada, excluye en el art. 19.2.e) de la regulación armonizada, con independencia del valor estimado del contrato, los siguientes servicios jurídicos que, no obstante, quedan sometidos a la aplicación de la LCSP:

$1 .^{\circ}$ La representación y defensa legal de un cliente por un procurador o un abogado, ya sea en un arbitraje o una conciliación celebrada en un Estado o ante una instancia internacional de conciliación o arbitraje, o ya sea en un procedimiento judicial ante los órganos jurisdiccionales o las autoridades públicas de un Estado o ante órganos jurisdiccionales o instituciones internacionales.

2. ${ }^{\circ}$ El asesoramiento jurídico prestado como preparación de uno de los procedimientos mencionados en el apartado anterior de la presente letra, o cuando exista una probabilidad alta de que el asunto sobre el que se asesora será objeto de dichos procedimientos, siempre que el asesoramiento lo preste un abogado.

3. Los servicios de certificación y autenticación de documentos que deban ser prestados por un notario público.

4. Los servicios jurídicos prestados por administradores, tutores u otros servicios jurídicos cuyos prestadores sean designados por un órgano jurisdiccional o designados por ley para desempeñar funciones específicas bajo la supervisión de dichos órganos jurisdiccionales.

9 SANMARTíN MORA, M. A. (2018): "La contratación de prestaciones de carácter intelectual en la Ley 9/2017 de contratos del sector público". Observatorio de Contratación Pública. http://www.obcp.es/index.php/mod.opiniones/mem.detalle/id.342/relcategoria.121/relmenu.3/chk.22526a1a262b201d1ee7b78e398eb1e7 (consultado: 15-06-2018). 
REALA. Nueva Época - N. 11, Abril-Septiembre 2019 - ISSN: 1989-8975 - DOI: 10.24965/reala.v0i11.10570 - [Págs. 184-203]

La contratación de los servicios jurídicos en la ley 9/2017, de 8 de noviembre, de contratos del sector público

Jesús Rubio Beltrán

5. ${ }^{\circ}$ Otros servicios jurídicos que estén relacionados, incluso de forma ocasional, con el ejercicio del poder público.

Al contrario, sí que están sujetos a regulación armonizada el resto de servicios jurídicos, distintos de los antes señalados, cuyo importe sea superior a 750.000 euros y estén incluidos en el Anexo IV (servicios sociales y otros servicios específicos), con los Códigos CPV 79100000-5 a 79140000-7.

Y pese a que la Directiva permitía para estos servicios la exclusión en los supuestos del art. 10.d), y la regulación de un procedimiento especifico simplificado para determinados servicios jurídicos, la LCSP ni los ha excluido, ni ha regulado ningún procedimiento específico.

Por último, la LCSP recoge algunas previsiones que resultan aplicables en virtud de que los servicios jurídicos están incluidos dentro de los servicios especiales del Anexo IV de la LCSP. Son previsiones de poca y escasa trascendencia y que, en ningún caso, sustituyen el procedimiento general de contratación aplicable a la contratación de los servicios jurídicos por el sector público: si se usa un anuncio de información previa este podrá abarcar un plazo superior a 12 meses (art. 134.6), y la modificación de estos contratos no exige publicación en el Diario Oficial de la Unión Europea (art. 207.3) ${ }^{10}$.

\subsection{El tratamiento de los servicios jurídicos en otros países de la UE}

La Directiva 2014/24/UE reconoce unas características intrínsecas especiales en la prestación de determinados servicios jurídicos que conllevan la exigencia de un tratamiento específico para este tipo de servicios que no queda cubierto por las condiciones, más restrictivas, que impone la normativa de contratación pública.

El Considerando 25 de la Directiva justifica la exclusión a la que se refiere el art. 10.d) en el hecho de que el mercado de los servicios jurídicos es eminentemente un mercado nacional porque el Derecho varía en cada Estado miembro, y no es éste un mercado que se abra a la concurrencia de operadores de otros Estados. También es esa la razón por la que la Directiva aumenta el umbral económico para la aplicación de la regulación armonizada a los servicios jurídicos. El legislador europeo ha ponderado los principios de la contratación pública y ha considerado que no siempre hay que abrir las licitaciones o hay que hacerlo con el mismo grado de publicidad y garantías. El legislador europeo no aplica las medidas y garantías previstas en las Directivas, o las pondera en su justa medida, cuando las circunstancias del mercado no exigen su protección. Y así se ha considerado en el caso de la prestación de los servicios jurídicos.

En el Derecho comparado existen ejemplos claros de aplicación de este modo de interpretar la Directiva que pueden ser extrapolados y copiados a nuestro Derecho nacional.

En Francia la regulación de este tipo de servicios tiene sus especificidades. Sin perjuicio de la exclusión de los servicios públicos de la regulación de los servicios legales de representación de las reglas de la Contratación Pública, este tipo de servicios quedan sometidos a algunas reglas de procedimiento que derivan de que el objeto del contrato principal se refiera solo a los servicios legales de representación legal de un cliente por un abogado en un procedimiento legal, en el sentido de la exclusión prevista en el art. 10.d) de la Directiva 2014/24/UE, a los que se refiere la Directiva 77/249/CEE del Consejo, de 22 de marzo de 1977, dirigida a facilitar el ejercicio efectivo de la libre prestación de servicios por los abogados, en cuyo caso quedan excluidos de su aplicación, o bien si los servicios se refieren a un objeto más amplio que esos concretos servicios jurídicos e incorporan otro tipo de servicios, en cuyo caso quedan sometidos a la aplicación de la norma y a unas reglas específicas de procedimiento, igual que el resto de servicios.

La regulación de los servicios jurídicos, que denomina «servicios legales representativos de contratación pública», se encuentra en el art. 29, Décret núm. 2016-360 du 25 mars 2016 relatif aux marchés publics ${ }^{11}$.

En Alemania, aprovechando la posibilidad de exclusión de determinados servicios jurídicos prevista en el art. 10.d) de la Directiva 2014/24/UE, a los que se refiere la Directiva 77/249/CEE del Consejo, de 22 de marzo de 1977, los servicios jurídicos se excluyen cuando regulan la adjudicación de contratos públicos por poderes adjudicadores.

10 SANMARTíN MORA, M. A. (2018): "La contratación de prestaciones de carácter intelectual en la Ley 9/2017 de contratos del sector público". Observatorio de Contratación Pública. http://www.obcp.es/index.php/mod.opiniones/mem.detalle/id.342/relcategoria.121/relmenu.3/chk.22526a1a262b201d1ee7b78e398eb1e7 (consultado: 15-06-2018).

${ }_{11}$ https://www.legifrance.gouv.fr/eli/decret/2016/3/25/EINM1600207D/jo/texte (consultado: 15-06-2018). 
La regulación de la exclusión se encuentra en el art. 116 de la Ley de Defensa de la Competencia (Gesetz gegen Wettbewerbsbeschränkungen in der Fassung der Bekanntmachung von 26. Júnior 2013 (BGbl. I S. 1750, 3245).

Se indica que están excluidos los contratos que celebran poderes adjudicadores siempre que tengan por objeto servicios jurídicos cuando afecten a las siguientes prestaciones concretas:

a) Representaciones por un abogado:

aa) En procedimientos judiciales o administrativos tanto de carácter nacional como internacional.

bb) Procedimientos de arbitraje o conciliación nacional o internacional.

b) Asesoramiento por un abogado, siempre que sea para preparar una representación de las indicadas en el apartado anterior o cuando puedan darse circunstancias o exista una alta probabilidad de que acabe abriéndose un procedimiento de los indicados en el apartado anterior.

c) Actividades asumidas por notario: fe pública y certificados.

d) Actividades realizadas en el marco de un procedimiento judicial (contratar a expertos, etc.) o servicios jurídicos que solicita un órgano judicial o que impone la Ley.

e) Actividades que exigen el ejercicio de potestades públicas, aunque sea parcialmente.

Es decir, se recoge de forma clara y meridiana la exclusión de los servicios jurídicos, y de estos servicios en concreto, que coinciden con los previstos en la Directiva, de la aplicación del derecho alemán previsto en la Ley de la Competencia para la contratación de los poderes adjudicadores.

$\mathrm{Y}$, por último, también en Italia se excluyen los servicios jurídicos del mismo modo que en el Derecho alemán y francés.

El art. 17.1.d) del Codice dei Contratti Pubblici12, que entró en vigor el 19 de abril de 2016, una vez incorporada la Directiva 2014/24/UE, indica que las disposiciones del presente código no se aplicarán a los contratos y a las concesiones de los servicios en relación a los servicios legales a los que se refiere el art. 10.d) de la Directiva 2014/24/UE.

En definitiva, la propia Directiva 2014/24/UE abre a los Estados miembros, reconociendo que el mercado de los servicios jurídicos es eminentemente nacional y de poco o escaso interés para el mercado, la posibilidad de excluir de su aplicación los servicios jurídicos descritos en el art. 10.d) de la Directiva. El legislador nacional debería tomar nota de este modo de actuar e interpretar las Directivas en esos mismos términos para su transposición a las normas nacionales.

\section{ALGUNOS ELEMENTOS DIFERENCIADORES EN LA CONFIGURACIÓN DEL CONTRATO DE SERVICIOS JURÍDICOS}

\subsection{El objeto del contrato de servicios jurídicos}

La calificación de un contrato es una consecuencia directa del principio de legalidad contenido en el art. $103 \mathrm{CE}$, y no puede quedar al albur del órgano de contratación, sino que requiere un detenido estudio y análisis del contenido de las prestaciones de su objeto ${ }^{13}$.

Los contratos de servicios jurídicos se califican en derecho común como de arrendamiento de servicios conforme a lo dispuesto en el art. 1544 del Código Civil: «En el arrendamiento de obras o servicios, una de las partes se obliga a ejecutar una obra o a prestar a la otra un servicio por precio cierto».

En el ámbito de la contratación pública los servicios jurídicos constituyen uno de los contratos típicos del sector público cuyo ámbito ha quedado delimitado al definir el concepto de servicios jurídicos en el capítulo 1.

En relación al objeto del contrato, queda por determinar, y a priori resulta complejo, las prestaciones que puede incluir el objeto del contrato de servicios jurídicos así definido conforme al art. 99 LCSP. Las necesidades de asesoría y representación en juicio pueden ser complejas, difíciles de determinar en contenido y duración, confrontan con el fraccionamiento del contrato, y deben respetar los principios que rigen la contratación del sector público contenidos en el art. 1 LCSP.

\footnotetext{
12 https://www.codiceappalti.it/documenti/CodiceAppalti.it_Ultimo_aggiornamento.pdf (consultado: 15-06-2018).

13 Acuerdo 343/2014, de 20 de junio, del Tribunal Administrativo de Contratos Públicos de Aragón.
} 
El art. 99 LCSP prescribe que el objeto de los contratos del sector público deberá ser determinado y que no podrá fraccionarse con la finalidad de disminuir la cuantía del mismo y eludir así los requisitos de publicidad o los relativos al procedimiento de adjudicación que correspondan y, además, siempre que la naturaleza o el objeto del contrato lo permitan, deberá preverse la realización independiente de cada una de sus partes mediante su división en lotes.

El concepto de «unidad funcional» es el que determina el contenido del principio de objeto completo en cada caso: unidad funcional y «totalidad del objeto del contrato» son lo mismo. Esto significa que sólo si existe más de una unidad funcional en el marco del objeto contractual sería posible el fraccionamiento o la división por lotes ${ }^{14}$.

El objeto del contrato de servicios jurídicos, de asistencia y representación en juicio, puede incorporar actuaciones e intervenciones diversas que en todo caso afectan al ámbito competencial del poder adjudicador, y puede comprender tanto la asistencia jurídica para preparar el proceso (comparecencia y personación en el proceso, preparación del expediente a remitir al órgano judicial, emplazamiento de interesados en el recurso, etc.), como la propia representación en juicio (formulación de demanda y contestación, pruebas, testigos, recursos frente a autos y sentencias, etc.), en cualquiera de los órdenes jurisdiccionales.

Las variadas actuaciones que pueden incorporarse al objeto de este contrato de servicios impiden y dificultan que el órgano de contratación pueda determinar de forma exacta y precisa el contenido completo de la asistencia y representación en juicio en el momento de la preparación de la licitación. Es decir, si el objeto debe incluir todas las actuaciones referidas o las mismas pueden o deben ser objeto de contratos independientes, o bien, si procede su licitación en lotes ${ }^{15}$. Sería así posible establecer respecto a este tipo de contrato de servicios su licitación en lotes (por ejemplo, tomando como referencia las especialidades procedimentales y procesales de las distintas ramas del Derecho (penal, administrativo, civil, mercantil y laboral), lo que podría determinar la división de un contrato de asistencia jurídica para la defensa en juicio de una entidad en lotes en atención a las diversas especialidades o ramas del Derecho. Y también sería posible establecer la división en lotes del objeto del contrato en atención a la complejidad técnica de los asuntos jurídicos tratados, o bien de la cuantía económica de los mismos.

De este modo, queda constatada la dificultad que supone para el órgano de contratación la determinación del objeto del contrato de servicios jurídicos, de asistencia y representación en juicio, en el modo exigido por el art. 99 LCSP.

\subsection{El precio en el contrato de servicios jurídicos}

El art. 100 LCSP, referido al presupuesto base de licitación, también puede plantear algún problema en relación a su determinación para este tipo de contratos de servicios jurídicos. Por presupuesto base de licitación se entenderá el límite máximo de gasto que en virtud del contrato puede comprometer el órgano de contratación, incluido el IVA, salvo disposición en contrario, y en el momento de elaborarlo, los órganos de contratación cuidarán de que el presupuesto base de licitación sea adecuado a los precios del mercado. Y es en este punto donde hay que preguntarse cuáles son los precios de mercado en los contratos de servicios jurídicos de asistencia y defensa en juicio ${ }^{16}$.

A tal efecto, el art. 100 LCSP prescribe que el presupuesto base de licitación se desglosará indicando en el pliego de cláusulas administrativas particulares o documento regulador de la licitación los costes directos e indirectos y otros eventuales gastos calculados para su determinación. En los contratos en los que, el coste de los salarios de las personas empleadas para su ejecución, formen parte del precio total del contrato, el presupuesto base de licitación indicará de forma desglosada y con desagregación de género y categoría profesional los costes salariales estimados a partir del convenio laboral de referencia, cuestión ésta difícil de aplicar al contrato de servicios jurídicos pese a que el servicio se presta por personas físicas, el abogado.

Pero respecto a la determinación del precio del contrato y en un sentido distinto, el art. 44 del EAB, al remitir la fijación del precio del contrato a la libertad de las partes, determina que «el abogado tiene derecho a

14 AGUDO GONZALEZ, J. (2013): "El Fraccionamiento de los Contratos: Invalidez y Fraude de Ley". Revista de Estudios Locales (CUNAL), núm. 161, págs. 147-181.

${ }_{15}$ Acuerdo del Tribunal Administrativo de Contratación Pública de la Comunidad de Madrid. Resolución núm. 65/2018, de 28 de febrero de 2018

${ }^{16}$ Acuerdo del Tribunal Administrativo de Contratación Pública de la Comunidad de Madrid. Resolución núm. 65/2018, de 28 de febrero de 2018. 
REALA. Nueva Época - N. 11, Abril-Septiembre 2019 - ISSN: 1989-8975 - DOI: 10.24965/reala.v0i11.10570 - [Págs. 184-203]

una compensación económica adecuada por los servicios prestados, así como al reintegro de los gastos que se le hayan causado. La cuantía de los honorarios será libremente convenida entre el cliente y el abogado, con respeto a las normas deontológicas y sobre competencia desleal. A falta de pacto expreso en contrario, para la fijación de los honorarios se podrán tener en cuenta, como referencia, los baremos orientadores del Colegio en cuyo ámbito actúe, aplicados conforme a las reglas, usos y costumbres del mismo, normas que, en todo caso, tendrán carácter supletorio de lo convenido y que se aplicarán en los casos de condena en costas a la parte contraria. Dicha compensación económica podrá asumir la forma de retribución fija, periódica o por horas. Respecto a las costas recobradas de terceros se estará a lo que libremente acuerden las partes, que a falta de pacto expreso habrán de ser satisfechas efectivamente al abogado. Se prohíbe en todo caso la cuota litis en sentido estricto, entendiéndose por tal el acuerdo entre el abogado y su cliente, previo a la terminación del asunto, en virtud del cual éste se compromete a pagarle únicamente un porcentaje del resultado del asunto, independientemente de que consista en una suma de dinero o cualquier otro beneficio, bien o valor que consiga el cliente por ese asunto».

La determinación del precio del contrato también puede verse dificultada por la indefinición del objeto al que se ha hecho referencia en el epígrafe precedente, afectando con ello también a la obligación de determinar el valor estimado del contrato. Y a este respecto, el art. 101, referido al valor estimado, que nos servirá de valor de referencia para determinar el concreto régimen de publicidad al que debe someterse la licitación del contrato de servicios, deberán tenerse en cuenta, como mínimo, además de los costes derivados de la aplicación de las normativas laborales vigentes, otros costes que se deriven de la ejecución material de los servicios, los gastos generales de estructura y el beneficio industrial. Asimismo, deberán tenerse en cuenta cualquier forma de opción eventual y las eventuales prórrogas del contrato.

$Y$ así, debemos plantearnos también si es posible prorrogar un contrato de asistencia y representación en juicio o, si en origen, como se apuntó al analizar el objeto de este contrato, éste debe incluir todos los recursos e instancias posibles, aunque luego se desista de su ejercicio, y ello al efecto de determinar el valor estimado del contrato, y con ello el régimen de publicidad al que debe someterse la licitación.

Debe hacerse referencia también a que en materia de honorarios de los servicios de asistencia y representación en juicio han desaparecido los antaño denominados criterios orientativos en materia de honorarios que establecían el devengo de unas determinados cuantías, bien fijas o variables, en función de las actuaciones, referidas a tipología y orden jurisdiccional, del abogado interviniente.

El ámbito natural de aplicación de los criterios de honorarios que en la actualidad publican los Colegios de Abogados ha de ser el de las impugnaciones de honorarios en las tasaciones de costas, en el que la determinación de los honorarios mediante acuerdos alcanzados entre abogado y cliente queda excluida por ser un tercero, el condenado en costas, quién debe satisfacer no ya los honorarios del abogado -que sabido es que en todo caso corresponde al cliente-, sino el importe que por tal concepto sea susceptible de ser incluido en una tasación de costas y exigible a la parte condenada en el proceso judicial.

Pero traída esta argumentación al momento de fijación del precio del contrato de servicios jurídicos, de asistencia y representación en juicio, hay que preguntar cómo encaja este sistema de determinación de la cuantía de los honorarios regida por el principio de libertad y el acuerdo entre abogado y cliente ${ }^{17}$, y también, en caso de discrepancia en el precio fijado, u oposición a su cuantía, cómo se coordinan los criterios en materia de honorarios, con los criterios de fijación del precio y el valor estimado del contrato establecidos en el art. 100 y 309 LCSP. A priori, estos criterios en materia de honorarios tampoco encajan con la prestación de este servicio y con la obligación del órgano de contratación de fijar el precio y el valor estimado del contrato con carácter previo a su licitación.

\subsection{Las exigencias de solvencia en el contrato de servicios jurídicos}

Es fundamental en la preparación de la licitación de un contrato de servicios jurídicos la determinación de los criterios de solvencia y de los criterios de adjudicación del contrato. Un elemento fundamental y necesario de este contrato es la mutua confianza ${ }^{18}$. Es por ello que se hace imprescindible en la preparación de

17 Acuerdo del Tribunal Administrativo de Contratación Pública de la Comunidad de Madrid. Resolución núm. 65/2018, de 28 de febrero de 2018.

18 FERNANDEZ LEÓN, Ó. (2014): "La confianza, fundamento de la relación abogado-cliente". Legaltoday (10 de febrero de 2014). http://www.legaltoday.com/gestion-del-despacho/estrategia/articulos/la-confianza-fundamento-de-la-relacion-entre-abogado-cliente (consultado: 15-06-2018). 
REALA. Nueva Época - N. 11, Abril-Septiembre 2019 - ISSN: 1989-8975 - DOI: 10.24965/reala.v0i11.10570 - [Págs. 184-203]

la licitación de este contrato tratar de encajar este elemento subjetivo. La confianza se demuestra a través de los trabajos previos realizados por el profesional a contratar.

La solvencia técnica o profesional en los contratos de servicios, también en los jurídicos, se refiere a los conocimientos técnicos, eficacia, experiencia y fiabilidad de los empresarios para la prestación del servicio (art. 90 LCSP), y que se concreta en la exigencia por el órgano de contratación de uno o varios de los siguientes medios:

a) Una relación de los principales servicios o trabajos realizados de igual o similar naturaleza que los que constituyen el objeto del contrato en el curso de, como máximo los tres últimos años, en la que se indique el importe, la fecha y el destinatario, público o privado de los mismos.

b) Indicación del personal técnico o de las unidades técnicas, integradas o no en la empresa, participantes en el contrato, especialmente aquellos encargados del control de calidad.

c) Descripción de las instalaciones técnicas, de las medidas empleadas por el empresario para garantizar la calidad y de los medios de estudio e investigación de la empresa.

d) Cuando se trate de servicios o trabajos complejos o cuando, excepcionalmente, deban responder a un fin especial, un control efectuado por el órgano de contratación o, en nombre de este, por un organismo oficial u homologado competente del Estado en que esté establecido el empresario, siempre que medie acuerdo de dicho organismo.

e) Títulos académicos y profesionales del empresario y de los directivos de la empresa y, en particular, del responsable o responsables de la ejecución del contrato, así como de los técnicos encargados directamente de la misma, siempre que no se evalúen como un criterio de adjudicación.

f) En los casos adecuados, indicación de las medidas de gestión medioambiental que el empresario podrá aplicar al ejecutar el contrato.

g) Declaración sobre la plantilla media anual de la empresa y del número de directivos durante los tres últimos años, acompañada de la documentación justificativa correspondiente cuando le sea requerido por los servicios dependientes del órgano de contratación.

h) Declaración indicando la maquinaria, material y equipo técnico del que se dispondrá para la ejecución de los trabajos o prestaciones, a la que se adjuntará la documentación acreditativa pertinente cuando le sea requerido por los servicios dependientes del órgano de contratación.

i) Indicación de la parte del contrato que el empresario tiene eventualmente el propósito de subcontratar.

En relación a la experiencia, como solvencia técnica, se ha venido admitiendo, con algunas reservas, la experiencia previa en determinadas materias que afectaban al conocimiento del derecho local o a un ámbito específico de especialización jurídica, pero sin que tal exigencia de experiencia pueda restringir de forma desproporcionada el acceso a la licitación y la limitación de la competencia, ni resultar desproporcionada en relación al fin que se persigue. Nada impide tampoco que, en relación a la exigencia de personal técnico cualificado determinado en el pliego, el mismo pueda ser integrado con medios profesionales externos, adicionales a los mínimos exigidos en el pliego, y sin que sea admisible la subcontratación, en atención a la naturaleza y condiciones del contrato ${ }^{19}$.

También, en relación a la experiencia exigida al licitador en la defensa jurídica a entidades locales con población de derecho superior a 20.000 habitantes, el TACRC ha mantenido el criterio señalado concluyendo que dicha exigencia restringe excesivamente la competencia al no prever otras medidas alternativas como acreditar un número superior de contratos en municipios de población inferior a 20.000 habitantes o haber trabajado para entidades que sí hubieran suscrito contratos con municipios de más de 20.000 habitantes, anulando esta exigencia. También considera este Tribunal que restringe excesivamente la competencia, y por ende resulta desproporcionado, que no se permitan otros medios para probar la experiencia profesional en el ámbito administrativo más que el haber estado colegiado como abogado ejerciente durante el tiempo de 10 años. Ello restringe el acceso a la licitación a quienes tienen amplios conocimientos jurídico-administrativos adquiridos como funcionarios públicos, así como el hecho de que múltiples profesionales jurídicos por cuenta ajena no están colegiados como ejercientes. Y así no cabe concluir que el único modo en que una persona puede adquirir experiencia en el funcionamiento de la Administración sea como abogado colegiado ${ }^{20}$.

19 Resolución núm. 207, de 14 de marzo de 2014, del Tribunal Administrativo Central de Recursos Contractuales.

20 Resolución núm. 238/2016, de 1 de abril de 2016, del Tribunal Administrativo Central de Recursos Contractuales. 
Sin embargo, la experiencia previa, referida a los títulos académicos y profesionales del empresario y de los directivos de la empresa y, en particular, del responsable o responsables de la ejecución del contrato, así como de los técnicos encargados directamente de la misma, sí que puede ser considerada al determinar la solvencia, pero siempre que no se evalúe como un criterio de adjudicación.

El art. 90 LCSP también refiere la solvencia técnica a la «fiabilidad» como término equivalente a seguridad y obtención de resultados satisfactorios, pero distinto al elemento confianza, y fundamental, pese a ser un elemento subjetivo, en la relación entre abogado y cliente.

La experiencia que podría equipararse a confianza, de ser exigida no respecto a los principales servicios o trabajos realizados de igual o similar naturaleza que los que constituyen el objeto del contrato de cualquier destinatario, público o privado, sino sólo de los servicios de estas características realizados para el órgano de contratación, viene prohibida por el art. 40.b) LCSP que determina que son causas de anulabilidad, no ya de nulidad como refería el art. 32 TRLCSP, todas aquellas disposiciones, resoluciones, clausulas o actos emanados de cualquier poder adjudicador que otorguen, de forma directa o indirecta, ventajas a las empresas que hayan contratado previamente con cualquier Administración ${ }^{21}$. Esta prohibición obliga a descartar la posibilidad de integrar el elemento de la confianza en el abogado como criterio de solvencia técnica.

\subsection{La experiencia como criterio de adjudicación en el contrato de servicios jurídicos}

Y respecto a los criterios de adjudicación del contrato de servicios jurídicos, el art. 145.5 y 6 LCSP no ha alterado los requisitos que deben cumplir los criterios de adjudicación para resultar válidos, debiendo estar vinculados al objeto del contrato y referirse a aspectos de la oferta y ser publicados, además, de forma previa.

Atendiendo al interés público que persigue el contrato y a su objeto, el órgano de contratación puede fijar diferentes criterios de valoración y su ponderación para establecer un sistema de comparación de ofertas que permita lograr la mayor eficiencia en la utilización de los recursos públicos, atendiendo a la calidad y al precio, para obtener la oferta más ventajosa.

La experiencia en la ejecución del contrato de servicios jurídicos puede constituir, con matices, un criterio de solvencia técnica, pero no puede ser un criterio de valoración, dado que no se refiere o proyecta sobre la oferta concreta, sino que se refiere a aspectos intrínsecos del licitador. No cabe considerar como criterio de valoración circunstancias relativas a la solvencia del licitador. Y no cabe, además, introducir criterios abiertos genéricos y arbitrarios que no permitan un control posterior de la adjudicación ${ }^{22}$.

Como novedad, el art. 145.2.2 LCSP permite ahora incorporar como criterio cualitativo para evaluar la mejor relación calidad-precio aspectos medioambientales o sociales, vinculados al objeto del contrato, y que podrán ser, entre otros, referidos a la organización, cualificación y experiencia del personal adscrito al contrato que vaya a ejecutar el mismo, siempre y cuando la calidad de dicho personal pueda afectar de manera significativa a su mejor ejecución ${ }^{23}$.

Esta opción abre una nueva vía para la contratación de los servicios jurídicos, de asistencia y representación en juicio, y podrá ser considerada cuando la calidad profesional de los equipos humanos que se adscriban al contrato pueda configurarse como una característica intrínseca de la oferta vinculada al objeto del contrato, en particular, en los servicios de carácter intelectual.

Sin embargo, llevados estos criterios de valoración que se analizan al elemento clave en la relación abogado-cliente, la confianza, de nuevo encontramos dificultades para poder valorar de forma objetiva un elemento subjetivo. La posibilidad apuntada en el párrafo precedente lo es respecto a la calidad de los equipos humanos adscritos al contrato (a su experiencia previa y currículum), pero no al elemento de la confianza, que, como elemento subjetivo, se antoja otra vez difícil su valoración y ponderación, su reflejo en los pliegos de licitación y su publicación previa como exige la LCSP.

\subsection{La duración del contrato de servicios jurídicos}

Con carácter general, la duración de los contratos del sector público debe establecerse teniendo en cuenta la naturaleza de las prestaciones, las características de su financiación y la necesidad de someter

\footnotetext{
21 MESA VILA, M. El artículo se publicó en el número 47 de la Revista General de Derecho Administrativo (lustel, enero 2018 ).

22 Resolución núm. 238/2016, de 1 de abril de 2016, del Tribunal Administrativo Central de Recursos Contractuales.

23 CHINCHILLA PEINADO, J. A. (2018): "La preparación del contrato". La nueva Ley de Contratos del Sector Público, págs. 82115. Ed. Iurisutilitas.es.
} 
REALA. Nueva Época - N. 11, Abril-Septiembre 2019 - ISSN: 1989-8975 - DOI: 10.24965/reala.v0i11.10570 - [Págs. 184-203]

periódicamente a concurrencia su realización, así como la necesidad de que el expediente se refiera a la totalidad de su objeto.

La duración máxima de los contratos de servicios, también de los jurídicos, se encuentra limitada a cinco años, incluyendo las posibles prórrogas que el órgano de contratación pudiera acordar respetando las condiciones y límites establecidos en las respectivas normas presupuestarias que sean aplicables al órgano contratante (art. 29.4 LCSP).

Por su parte, el art. 29.8 LCSP señala que los contratos menores definidos en el art. 118 no podrán tener una duración superior a un año ni ser objeto de prórroga.

No obstante, el apartado 4, inciso final, del referido art. 29 admite la posibilidad de que cuando al vencimiento de un contrato no se hubiera formalizado el nuevo contrato que garantice la continuidad de la prestación a realizar por el contratista como consecuencia de incidencias resultantes de acontecimientos imprevisibles para el órgano de contratación producidas en el procedimiento de adjudicación y existan razones de interés público para no interrumpir la prestación, se podrá prorrogar el contrato originario hasta que comience la ejecución del nuevo contrato y en todo caso por un periodo máximo de nueve meses, sin modificar las restantes condiciones del contrato, siempre que el anuncio de licitación del nuevo contrato se haya publicado con una antelación mínima de tres meses respecto de la fecha de finalización del contrato originario, posibilidad de difícil acomodo al contrato de servicios jurídicos de asistencia y representación en juicio, dado que no se trata de un servicio continuado o recurrente.

Sin embargo, debe denunciarse que se ha eliminado en la LCSP la referencia expresa, como hacía el art. 303.3 del TRLCSP, a la posibilidad de que los contratos para la defensa jurídica y judicial de la Administración tuvieran la duración precisa para atender adecuadamente sus necesidades, reconociendo con ello una de las particularidades de este tipo de servicios, a saber, que su duración puede ser indeterminada.

La dificultad para determinar la duración de estos contratos viene dada por la complejidad de la defensa jurídica y judicial, y por la limitación que supone la prohibición de fraccionamiento del contrato.

Es por ello necesario determinar de forma previa y precisa ${ }^{24}$ la naturaleza y la extensión de las necesidades que pretenden cubrirse mediante el contrato de servicios proyectado, así como la idoneidad de su objeto y contenido para satisfacerlas, dando cumplimiento a la obligación impuesta por el art. 99 LCSP. Es decir, los contratos de servicios jurídicos del sector público deben integrar todas las prestaciones que sean precisas para alcanzar su fin.

De esta forma, para evitar posibles fraccionamientos del objeto del contrato, además de definir el objeto del contrato como prestaciones que sean susceptibles de un aprovechamiento individualizado, se deberá tener cuenta también la vertiente temporal de la prestación, así como la posible incidencia que la división o el fraccionamiento del contrato podrían tener sobre los principios (y obligaciones) de publicidad de la licitación y sobre la concurrencia.

La duración de los contratos de defensa jurídica y judicial puede suponer una necesidad continuada en el tiempo por lo que establecer la duración de un contrato de forma limitada, un año o dos, por ejemplo, puede suponer un fraccionamiento en el tiempo del objeto del contrato que posibilita, en detrimento de los principios de publicidad, concurrencia y libertad de acceso a las licitaciones, adjudicaciones sucesivas al mismo adjudicatario mediante un procedimiento sin publicidad.

Es decir, la duración no depende de la naturaleza de las prestaciones sino de que no se sobrepase un importe que permita acudir a un procedimiento de adjudicación que deberá ser excepcional por contradecir el principio de publicidad que es garantía de la libre concurrencia (Cámara de Cuentas de Madrid. Informe de Fiscalización 2014).

La LCSP, una vez más, no ha considerado las características y peculiaridades de este tipo de servicios jurídicos, y la imposibilidad de determinar en origen, como consecuencia de la dificultad para determinar el objeto del contrato, la duración exacta de la asistencia y representación en juicio.

\subsection{Los procedimientos de licitación y la adjudicación el contrato}

Ya se ha dejado constancia de la dificultad que supone para el órgano de contratación determinar de forma exacta y precisa el contenido de esta asistencia y representación en juicio, y con ello las dificultades en la determinación del objeto del contrato de servicios jurídicos. Es decir, si comprende todas las actuaciones

24 Informe 14/2016, de 20 de julio, de la Junta Consultiva Contratación Administrativa de Aragón. 
REALA. Nueva Época - N. 11, Abril-Septiembre 2019 - ISSN: 1989-8975 - DOI: 10.24965/reala.v0i11.10570 - [Págs. 184-203]

o las mismas pueden o deben ser objeto de contratos independientes, o si procede su licitación en lotes. Es además una necesidad coyuntural del órgano de contratación y no una necesidad recurrente, lo que da idea de que su tratamiento no puede ser equivalente a otros servicios de carácter habitual o continuado.

Y el hecho de que éste sea un servicio no recurrente y puntual del órgano de contratación ha fomentado la utilización del contrato menor para su contratación por el sector público.

En la actualidad, se estima que es posible su utilización siempre que, de acuerdo con el art. 118 LCSP, no se supere el importe de 15.000 euros, no tenga una duración superior a un año, y no exista fraccionamiento del contrato.

La duración del contrato, derivada de la duración del proceso judicial, no obstante, puede dificultar la utilización de este procedimiento, máxime con las limitaciones adicionales objetivas y subjetivas ahora introducidas por la LCSP.

También era y es posible utilizar este procedimiento del contrato menor y contratar diferentes prestaciones cuando el importe total de todas ellas no supere el importe máximo establecido para el contrato menor y su duración no exceda de un año (Informe JCCA Cat. 14/2014, de 22 de julio).

No obstante, la utilización de este procedimiento ha sido muy discutida. El Informe 30/2012, de 7 de mayo, de la JCCA, cuestiona que se haya contratado mediante diferentes contratos menores adjudicados al mismo profesional la asistencia y defensa en juicio de la entidad local, concluyendo la necesidad de que el ayuntamiento, al tratarse de una necesidad recurrente y continuada, debió haber licitado un contrato que englobara todos los juicios. No obstante, dicha conclusión no puede ser considerada como norma general y sólo será aplicable cuando exista fraccionamiento ${ }^{25}$, es decir, cuando se rompa la unidad funcional. Esta unidad funcional puede existir y quedar justificada cuando nos encontramos ante un juicio de especial complejidad técnica.

Sin embargo, este procedimiento resolvía, en cierto modo, los problemas derivados de la urgencia y perentoriedad de los plazos establecidos para el ejercicio de acciones y la representación en juicio.

En relación a la utilización del procedimiento negociado sin publicidad, que en aplicación del art. 174.e) TRLCSP era posible cuando el valor estimado del contrato fuera inferior a 100.000 euros y existiera una razón de interés público para acudir a este procedimiento, la regulación actual de este procedimiento en la LCSP no permite su utilización (art. 168 LCSP).

Asimismo, en la regulación anterior, podía acudirse al procedimiento negociado sin publicidad cuando existiera un supuesto de imperiosa urgencia (art. 170.e) TRLCSP) que no pudiera resolverse a través de la tramitación de urgencia prevista en el art. 112 TRLCSP. No obstante, en relación a la defensa judicial y la interposición de sucesivos recursos ante instancias judiciales, tal motivo no puede tener la consideración de acontecimiento imprevisible que justifique su utilización (Informe JCCA 2/13, de 25 de julio de 2014).

E incluso, podría plantearse la utilización de este procedimiento sin publicidad en el supuesto del art. 170.d) TRLCSP, según el cual se podrá acudir al procedimiento negociado cuando «por razones técnicas o artísticas o por motivos relacionados con la protección de derechos de exclusiva, el contrato solo pueda encomendarse a un empresario determinado». Sin embargo, tampoco el hecho de que un determinado despacho de abogados haya llevado el pleito anteriormente o tenga un conocimiento específico de una materia concreta o de un asunto determinado, puede justificar el empleo de este procedimiento, por cuanto ese especial conocimiento no conlleva la exclusividad que comporta la aplicación al caso de este tipo de procedimiento, de uso tan restrictivo. Así, nada obsta a que existan otros despachos que también puedan llevar este pleito o tengan conocimientos para ello ${ }^{26}$.

No obstante, y pese a las limitaciones de uso planteadas, también este procedimiento resolvía de algún modo, las dificultades de contratación que se plantean en la contratación de este tipo de servicios jurídicos.

La aplicación del procedimiento abierto prevista por el art. 156 LCSP debe plantearse cuando nos encontramos ante una necesidad recurrente y continuada del órgano de contratación, y puede plantearse bien con un único objeto o bien mediante su división en lotes (tal y como se analizó al examinar el objeto del contrato).

La LCSP no recoge especialidad alguna para la tramitación del procedimiento abierto respecto a los servicios jurídicos por lo que, es evidente, los dilatados plazos de tramitación de este procedimiento, pese a la ampliación -o especialidad-, contenida en el art. 134.6 LCSP respecto a que si se usa un anuncio de

25 CHINCHILLA PEINADO, J. A. “La preparación del contrato”. La nueva Ley de Contratos del Sector Público, págs. 82-115. Ed. lurisutilitas.es.

26 Informe JCCA 30/2012, de 7 de mayo de 2012. 
REALA. Nueva Época - N. 11, Abril-Septiembre 2019 - ISSN: 1989-8975 - DOI: 10.24965/reala.v0i11.10570 - [Págs. 184-203]

información previa este podrá abarcar un plazo superior a 12 meses, o la reducción de plazos prevista con la tramitación de urgencia (art. 119 LCSP), no casan con la agilidad procedimental que demanda el objeto del contrato de servicios jurídicos y la inmediatez procesal.

El procedimiento abierto simplificado regulado en el art. 159 LCSP, y pese a que su tramitación es más rápida, tampoco resuelve los problemas apuntados, dado que entre las condiciones de licitación a incorporar en el pliego se encuentra la de que entre los criterios de adjudicación previstos en el pliego no haya ninguno evaluable mediante juicio de valor o, de haberlos, su ponderación no supere el veinticinco por ciento del total, salvo en el caso de que el contrato tenga por objeto prestaciones de carácter intelectual, como los servicios de ingeniería y arquitectura, en que su ponderación no podrá superar el cuarenta y cinco por ciento del total. Y como servicios intelectuales se citan, a título de ejemplo, los servicios de ingeniería y arquitectura.

Del análisis de los elementos del contrato de servicios jurídicos realizado se concluye que la finalidad del objeto de este tipo de contratos de servicios jurídicos es la obtención de un resultado en el que intervienen factores humanos, intelectuales y de estrategia, lo que llevan a caracterizar este servicio, al igual que otros, como un servicio de carácter intelectual. Esta caracterización impediría la utilización para la contratación de estos servicios del procedimiento abierto simplificado si se pretenden incorporar o valorar criterios como la calidad profesional de los equipos humanos que se adscriban al contrato y pueda configurarse como una característica intrínseca de la oferta vinculada al objeto del contrato, quedando limitada su ponderación, al porcentaje indicado, pese a su trascendencia como elemento fundamental de este contrato.

Tampoco se considera de aplicación el procedimiento abierto simplificado especial regulado en el art. 159.6 LCSP, del que se excluyen expresamente los servicios intelectuales.

Por último, y en lo que se refiere a la posibilidad de utilizar un acuerdo marco para la contratación de los servicios jurídicos, el art. 219 LCSP determina que uno o varios órganos de contratación del sector público podrán celebrar acuerdos marco con una o varias empresas con el fin de fijar las condiciones a que habrán de ajustarse los contratos que pretendan adjudicar durante un período determinado, que no podrá exceder de cuatro años, en particular por lo que respecta a los precios, y en su caso, a las cantidades previstas, siempre que el recurso a estos instrumentos no se efectúe de forma abusiva o de modo que la competencia se vea obstaculizada, restringida o falseada. Este sistema de racionalización técnica de la contratación podría utilizarse en los contratos de servicios jurídicos cuando el órgano de contratación tuviera la necesidad de contratar un volumen elevado de este tipo de servicios. En otro caso, y en particular en las entidades locales de pequeño tamaño, la complejidad técnica de este sistema de contratación desaconseja su utilización.

En conclusión, los procedimientos de licitación previstos por la LCSP para este tipo de servicios, y dado que no se regula ninguna especialidad para los servicios jurídicos, no pueden satisfacer las exigencias y particularidades que deben ser consideradas en la contratación de los servicios jurídicos. Los procedimientos previstos en la LCSP están ideados para la contratación de servicios ordinarios y recurrentes del órgano de contratación. Y sólo de considerar los servicios jurídicos como servicios intelectuales sería posible aplicar a su licitación las especialidades previstas por la LCSP, también escasas e insuficientes, para la contratación de los servicios intelectuales.

\section{LA NECESIDAD DE UN TRATAMIENTO DIFERENCIADO EN LA REGULACIÓN DE LOS SERVICIOS JURÍDICOS}

\subsection{El tratamiento diferenciado de algunos servicios en la LCSP: los denominados «servicios intelectuales»}

La LCSP recoge una serie de previsiones específicas para la adjudicación de los contratos de servicios que tienen por objeto prestaciones de carácter intelectual. Se reconoce expresamente «la naturaleza de prestaciones de carácter intelectual a los servicios de arquitectura, ingeniería, consultoría y urbanismo» en la DA 41 LCSP, no así a los servicios jurídicos.

La mayor parte de las especialidades que afectan a la contratación de los servicios intelectuales se incluyeron durante el debate parlamentario del Proyecto en el Congreso de los Diputados, a instancia de colegios, asociaciones y foros profesionales como los que firmaron en 2015 la «Declaración para la calidad en los servicios de la arquitectura y de la ingeniería», entre los que cabe destacar al Consejo Superior de 
REALA. Nueva Época - N.o 11, Abril-Septiembre 2019 - ISSN: 1989-8975 - DOI: 10.24965/reala.v0i11.10570 - [Págs. 184-203]

los Colegios de Arquitectos de España (CSCAE) ${ }^{27}$. El Consejo de Arquitectos ha trabajado en la LCSP desde el año 2011 elaborando una propuesta de reglamento para los Concursos de Proyectos presentada al Ministerio de Hacienda y de Fomento y que no fue considerada por estar pendiente la transposición de la Directiva 2014/24/UE de contratación pública. En el año 2015 se presentaron alegaciones al borrador del anteproyecto de Ley y el pasado mes de junio de 2017 se presentaron 13 enmiendas a todos los grupos parlamentarios. De igual forma estas enmiendas se presentaron al Ministerio de Fomento junto con los apoyos de 26 colegios y demarcaciones, 11 escuelas de arquitectura, 12 instituciones vinculadas con la arquitectura y la sociedad civil, 654 arquitectos y 11 ciudadanos defendiendo y apoyando las enmiendas del Colegio de Arquitectos. En total 714 cartas que representan a más de 60.000 arquitectos, estudiantes y ciudadanos interesados en que la calidad de la arquitectura en las ciudades prevalezca sobre criterios económicos en la contratación de estos servicios por las Administraciones Públicas ${ }^{28}$.

Las enmiendas presentadas ante los grupos parlamentarios y los diferentes actores en la tramitación de la LCSP resumen la posición histórica de los arquitectos y las reivindicaciones constantes de la profesión sobre la problemática en la adjudicación de los contratos del sector público y con esta nueva actuación ante el legislador han tratado y conseguido revertir definitivamente los graves problemas causados hasta ahora por una inconsecuente, inadaptada e impropia regulación sobre la licitación de los servicios de arquitectura.

En relación a los procedimientos de adjudicación de servicios intelectuales de especial complejidad, como es el caso de algunos servicios de arquitectura o de ingeniería, la LCSP considera adecuada la utilización del procedimiento restringido (art. 160.4 LCSP), y en aquellos que tengan por objeto la redacción de proyectos arquitectónicos, de ingeniería y urbanismo que revistan especial complejidad, los órganos de contratación deberán aplicar un concurso de proyectos (art. 183.3 LCSP), al que seguirá la tramitación de un procedimiento negociado sin publicidad con el ganador o ganadores del concurso (art. 168.d) LCSP). En ningún caso podrá utilizarse en la adjudicación de estos contratos la subasta electrónica (art. 143.2 LCSP). Y tampoco les resulta de aplicación el procedimiento abierto simplificado abreviado que regula el art. 159.6 LCSP.

Y en relación los criterios de adjudicación el precio no podrá ser el único factor determinante de la adjudicación debiendo utilizarse varios criterios (art. 145.3.g) LCSP). Los criterios de adjudicación utilizados tienen que permitir obtener prestaciones de gran calidad que respondan lo mejor posible a las necesidades planteadas, exigiendo respecto a los criterios de calidad que representen, al menos, el 51 por ciento de la puntuación asignable en la valoración de las ofertas (art. 145.4 LCSP). En el procedimiento abierto simplificado previsto en el art. 159.1.b) LCSP se exige que si se incluyen criterios evaluables mediante juicio de valor su ponderación no podrá superar el cuarenta y cinco por ciento del total. Y también, como ya se adelantó al hablar de los criterios de valoración, la posibilidad de incorporar como criterio cualitativo para evaluar la mejor relación calidad-precio aspectos medioambientales o sociales, vinculados al objeto del contrato, y que podrán ser, entre otros, referidos a la organización, cualificación y experiencia del personal adscrito al contrato que vaya a ejecutar el mismo, siempre y cuando la calidad de dicho personal pueda afectar de manera significativa a su mejor ejecución ${ }^{29}$.

Por último, la LCSP incorpora también otras especialidades en el procedimiento de contratación de los servicios denominados intelectuales relativos a la subsanación de errores, indemnizaciones y responsabilidades en el contrato de elaboración de proyectos de obras (art. 314 y 315 LCSP).

En definitiva, la LCSP regula un tratamiento diferenciado para la contratación de los servicios intelectuales introduciendo en su articulado especialidades procedimentales que permiten resolver y revertir los problemas de la licitación de los servicios de arquitectura e ingeniería.

Analizados los elementos que conforman el contrato de servicios jurídicos ha quedado acreditado que las características intrínsecas de este contrato, en particular la concurrencia de voluntades en la formalización del contrato como fiel reflejo de la mutua confianza que rige la prestación de este tipo de servicios, obligan a caracterizar esta prestación de un modo especial. Los servicios jurídicos de asesoría y represen-

27 SANMARTÍN MORA, M. A. (2018): "La contratación de prestaciones de carácter intelectual en la Ley 9/2017 de contratos del sector público". Observatorio de Contratación Pública. http://www.obcp.es/index.php/mod.opiniones/mem.detalle/id.342/relcategoria.121/relmenu.3/chk.22526a1a262b201d1ee7b78e398eb1e7 (consultado: 15-06-2018).

${ }_{28}$ Consejo Superior de los Colegios de Arquitectos de España (CSCAE). https://www.cscae.com/index.php/es/conoce-cscae/ area-juridica/enmiendas-a-la-ley-de-contratos-del-sector-publico (consultado: 15-06-2018).

${ }_{29}$ CHINCHILLA PEINADO, J. A. (2018): “La preparación del contrato”. La nueva Ley de Contratos del Sector Público. Ed. lurisutilitas. es (páginas 82-115). 
REALA. Nueva Época - N.o 11, Abril-Septiembre 2019 - ISSN: 1989-8975 - DOI: 10.24965/reala.v0i11.10570 - [Págs. 184-203]

tación en juicio en el ámbito de la contratación pública se refieren exclusivamente a los servicios prestados por abogados en cualquier ámbito o especialidad del derecho.

Respecto a sus elementos, se ha dejado constancia de que el objeto del contrato de servicios jurídicos, de asistencia y representación en juicio, puede incorporar actuaciones e intervenciones diversas que en todo caso afectan al ámbito competencial del poder adjudicador, y puede comprender tanto la asistencia jurídica para preparar el proceso (comparecencia y personación en el proceso, preparación del expediente a remitir al órgano judicial, emplazamiento de interesados en el recurso, etc.), como la propia representación en juicio (formulación de demanda y contestación, pruebas, testigos, recursos frente a autos y sentencias, etc.), en cualquiera de los órdenes e instancias jurisdiccionales. Y sobre esta categoría de servicios jurídicos y con este objeto -la representación en juicio y asesoría, y en relación al objeto del contrato, resulta tarea compleja, y así se ha demostrado, la determinación exacta de todas sus prestaciones.

En lo que se refiere al precio del contrato de servicios jurídicos, de asistencia y representación en juicio, no es fácil encajar el sistema de determinación de la cuantía de los honorarios regida por el principio de libertad y el acuerdo entre abogado y cliente (art. 44 EAB), y también, en caso de discrepancia en el precio fijado, u oposición a su cuantía, cómo se coordinan los criterios en materia de honorarios, con los criterios de fijación del precio y el valor estimado del contrato establecidos en el art. 100 y 309 LCSP. Estos criterios en materia de honorarios tampoco encajan con la prestación de este servicio y con la obligación del órgano de contratación de fijar el precio y el valor estimado del contrato con carácter previo a su licitación, y ello con el fin último de someter la licitación del servicio al régimen de publicidad que en atención al importe del valor estimado del contrato sea exigible.

El artículo $1 \mathrm{EAB}$ establece que la abogacía es una profesión libre e independiente que presta un servicio a la sociedad en interés público y que se ejerce en régimen de libre y leal competencia, por medio del consejo y la defensa de derechos e intereses públicos o privados, mediante la aplicación de la ciencia y la técnica jurídicas, en orden a la concordia, a la efectividad de los derechos y libertades fundamentales y a la justicia. En el ejercicio profesional, el abogado queda sometido a la normativa legal y estatutaria, al fiel cumplimiento de las normas y usos de la deontología profesional de la abogacía y al consiguiente régimen disciplinario colegial.

En definitiva, todos estos elementos que conforman el contrato de servicios jurídicos, de asistencia y representación en juicio, configuran y dotan a estos servicios de unas características especiales. La finalidad del objeto de este tipo de contratos de servicios jurídicos es la obtención de un resultado en el que intervienen factores humanos, intelectuales y de estrategia, lo que llevan a caracterizar este servicio, al igual que otros, como un servicio de carácter intelectual. Y esta caracterización de los servicios jurídicos como servicios intelectuales debe conducir a dotarlos de un tratamiento y de una regulación específica para su contratación por el sector público, o bien a su exclusión del ámbito de aplicación de la LCSP.

\subsection{El elemento formal del contrato de servicios jurídicos: la voluntad de las partes y la mutua confianza}

La mutua confianza, como apunta Manuel Mesa Mila ${ }^{30}$, es la base sobre la que se construye la relación entre abogado y cliente. Esta afirmación tiene su apoyo y fundamento jurídico en el art. 4 del Código Deontológico de la Abogacía ${ }^{31}$, previsto en el Estatuto de la Abogacía Española, que prescribe lo siguiente ${ }^{32}$ :

\section{«... Artículo 4. Confianza e integridad}

La relación entre el cliente y su abogado se fundamenta en la confianza y exige de éste una conducta profesional íntegra, que sea honrada, leal, veraz y diligente.

El abogado, está obligado a no defraudar la confianza de su cliente y a no defender intereses en conflicto con los de aquél.

30 MESA VILA, M. El artículo se publicó en el número 47 de la Revista General de Derecho Administrativo (lustel, enero 2018).

31 Código Deontológico de la Abogacía Española, adaptado al Estatuto General de la Abogacía Española, aprobado por Real Decreto 658/2001, de 22 de junio, aprobado en el Pleno de 27 de septiembre de 2002 y modificado en el Pleno de 10 de diciembre de 2002.

32 FERNANDEZ LEÓN, Ó. (2014): “La confianza, fundamento de la relación abogado-cliente". Legaltoday (10 de febrero de 2014). http://www.legaltoday.com/gestion-del-despacho/estrategia/articulos/la-confianza-fundamento-de-la-relacion-entre-abogado-cliente (consultado: 15-06-2018). 
REALA. Nueva Época - N. 11, Abril-Septiembre 2019 - ISSN: 1989-8975 - DOI: 10.24965/reala.v0i11.10570 - [Págs. 184-203]

La contratación de los servicios jurídicos en la ley 9/2017, de 8 de noviembre, de contratos del sector público

Jesús Rubio Beltrán

En los casos de ejercicio colectivo de la abogacía o en colaboración con otros profesionales, el abogado tendrá el derecho y la obligación de rechazar cualquier intervención que pueda resultar contraria a dichos principios de confianza e integridad o implicar conflicto de intereses con clientes de otros miembros del colectivo...».

La base de la confianza se configura de este modo como una obligación jurídica, pero con un carácter marcadamente personal y subjetivo. Sin embargo, la relación entre abogado y cliente va más allá de su marco normativo, pues en ella destaca, sobre todos los demás, un elemento esencial para la supervivencia de la misma: la confianza, y cuya ausencia o pérdida nos llevará inevitablemente a su extinción. Sin confianza no hay negocio jurídico. La relación del abogado con el cliente debe fundarse en la recíproca confianza (art. 13).

El Código Deontológico de la Abogacía Europea ${ }^{33}$ señala en su apartado 2.2, dedicado a la Confianza e Integridad Moral de la relación profesional, que: «No pueden existir relaciones de confianza si existen dudas en cuanto a la honradez, probidad, rectitud y veracidad del abogado. Para este último, estas virtudes tradicionales son obligaciones profesionales».

Y, finalmente, la jurisprudencia del Tribunal Supremo ha reiterado que la relación del cliente con su abogado está basada en la confianza de suerte que, desaparecida ésta, debe cesar dicha relación (STS de 3 de abril de 1990) ${ }^{34}$.

Por lo tanto, la confianza que informa la relación entre abogado y cliente será, en principio, producto de la necesidad del cliente en confiar en quien está dotado de una experiencia y conocimiento de la que él carece, confianza que se irá transformando y solidificando a través de la actuación del abogado que, conocedor de sus obligaciones y deberes, actuará comprometido con ellos entregándose a la defensa de los intereses de su cliente sin fisuras o incertidumbres, sin olvidarse, eso sí, que la confianza se construye lentamente y se destruye rápidamente, pues como decía Augusto Cury ${ }^{35}$, "La confianza es un edificio difícil de construir, fácil de demoler y muy difícil de reconstruir».

Nos encontramos, de este modo, ante un elemento fundamental de obligada presencia y que no puede quedar al margen de los contratos de servicios jurídicos del Sector Público. Pero ¿cómo encajamos un concepto tan marcadamente subjetivo e inherente y singular de cada persona en un procedimiento administrativo rígido y reglado como el procedimiento de adjudicación de contratos públicos previsto en la LCSP? ¿Es este elemento subjetivo suficiente para exigir y demandar un tratamiento diferenciado para la contratación de los servicios jurídicos o es necesario algún elemento adicional?

$Y$ aunque este elemento tenga difícil acomodo en la rigidez de un procedimiento administrativo de licitación de un contrato, es necesario averiguar si es posible su encaje, ya que se trata de un elemento fundamental y obligatorio, por mandato legal, de la relación jurídica entre abogado y cliente. El análisis efectuado sobre la posibilidad de trasladar el elemento confianza a la preparación del contrato de servicios jurídicos bien como solvencia técnica (epígrafe 3.3.), bien como criterios de adjudicación del contrato (epígrafe 3.4) obliga a concluir, casi la imposibilidad, de encajar este elemento fundamental del contrato de servicios jurídicos con la rigidez del procedimiento administrativo de contratación y con las exigencias de la LCSP.

\section{CONCLUSIONES FINALES}

La Directiva 2014/24/UE reconoce unas características intrínsecas especiales en la prestación de determinados servicios jurídicos, los referidos en el art. 10.d), que determinan un tratamiento específico para este tipo de servicios, y que supone la inaplicación de la misma a los contratos públicos de servicios jurídicos excluidos.

El Considerando 25 de la Directiva justifica la exclusión a la que se refiere el art. 10.d) en el hecho de que el mercado de los servicios jurídicos es eminentemente un mercado nacional porque el Derecho varía en cada Estado miembro, y no es éste un mercado que se abra a la concurrencia de operadores de otros Estados. También es esa la razón por la que la Directiva aumenta el umbral económico para la aplicación

${ }_{33}$ Código Deontológico de la Abogacía Europea, aprobado en sesión plenaria en Estrasburgo el 28 de octubre de 1988 por el Consejo de Abogados de la Comunidad.

${ }_{34}$ Tribunal Supremo, Sala Tercera, de lo Contencioso-administrativo, Sección 1. ${ }^{\text {a }}$, Sentencia de 3 abril de 1990. Ponente: DELGADO BARRIO, F. J. LA LEY 1876-JF/0000.

${ }_{35}$ Augusto Cury (Colina, Brasil, 2 de octubre de 1958) es un médico psiquiatra, psicoterapeuta y escritor brasileño en ejercicio desde 1980, autor de numerosos libros de Psicopedagogía y Psicología preventiva. 
REALA. Nueva Época - N. 11, Abril-Septiembre 2019 - ISSN: 1989-8975 - DOI: 10.24965/reala.v0i11.10570 - [Págs. 184-203]

de la regulación armonizada a los servicios jurídicos. El legislador europeo ha ponderado los principios de la contratación pública y ha considerado que no siempre hay que abrir las licitaciones o hay que hacerlo con el mismo grado de publicidad y garantías. El legislador europeo no aplica las medidas y garantías previstas en las Directivas, o las pondera en su justa medida, cuando las circunstancias del mercado no exigen su protección. Y así se ha considerado en la prestación de los servicios jurídicos.

Una vez transpuesta la Directiva por la LCSP, las exclusiones de los servicios jurídicos de su regulación contenidas en la Directiva no han sido atendidas por el legislador nacional, ni tan siquiera en la regulación de un régimen simplificado de contratación, como prevé la Directiva para determinados servicios jurídicos considerados como servicios específicos o especiales (los recogidos en el Anexo XIV de la Directiva y en el Anexo IV de la LCSP).

Analizados los elementos que conforman el contrato de servicios jurídicos ha quedado acreditado que las características especiales de este contrato, en particular la concurrencia de voluntades en la formalización del contrato como fiel reflejo de la mutua confianza que rige la prestación de este tipo de servicios, obligan a caracterizar esta prestación de servicios de manera especial. Los servicios jurídicos de asesoría y representación en juicio en el ámbito de la contratación pública se refieren exclusivamente a los servicios prestados por abogados en cualquier ámbito o especialidad del derecho.

Respecto a sus elementos, se ha dejado constancia de que el objeto del contrato de servicios jurídicos, de asistencia y representación en juicio, puede incorporar actuaciones e intervenciones diversas que en todo caso afectan al ámbito competencial del poder adjudicador, y puede comprender tanto la asistencia jurídica para preparar el proceso (comparecencia y personación en el proceso, preparación del expediente a remitir al órgano judicial, emplazamiento de interesados en el recurso, etc.), como la propia representación en juicio (formulación de demanda y contestación, pruebas, testigos, recursos frente a autos y sentencias, etc.), en cualquiera de los órdenes e instancias jurisdiccionales. Y sobre esta categoría de servicios jurídicos y con este objeto -la representación en juicio y asesoría, y en relación al objeto del contrato, resulta tarea compleja, y así se ha demostrado, la determinación exacta de todas sus prestaciones.

En lo que se refiere al precio del contrato de servicios jurídicos, de asistencia y representación en juicio, tampoco es fácil encajar el sistema de determinación de la cuantía de los honorarios regida por el principio de libertad y el acuerdo entre abogado y cliente (art. 44 EAB), y también, en caso de discrepancia en el precio fijado, u oposición a su cuantía, cómo se coordinan los criterios en materia de honorarios, con los criterios de fijación del precio y el valor estimado del contrato establecidos en el art. 100 y 309 LCSP. Estos criterios en materia de honorarios tampoco encajan con la prestación de este servicio y con la obligación del órgano de contratación de fijar el precio y el valor estimado del contrato con carácter previo a su licitación, y ello con el fin último de someter la licitación del servicio al régimen de publicidad que en atención al importe del valor estimado del contrato sea exigible.

No es posible iniciar la ejecución del contrato con carácter previo a su formalización (art. 153.6 LCSP), y esta previsión confronta con la inmediatez que exige, en su caso, la defensa en juicio o la interposición en plazo de un nuevo recurso judicial.

La finalidad del contrato de servicios jurídicos, en todo caso, está relacionada con el interés público que consiste en la defensa jurídica del poder adjudicador en el ejercicio de las competencias que le son propias.

En definitiva, todos estos elementos que conforman el contrato de servicios jurídicos, de asistencia y representación en juicio, configuran y dotan a estos servicios de unas características especiales. La finalidad del objeto de este tipo de contratos de servicios jurídicos es la obtención de un resultado en el que intervienen factores humanos, intelectuales y de estrategia, lo que llevan a caracterizar este servicio, al igual que otros, como un servicio de carácter intelectual. Y esta caracterización de los servicios jurídicos como servicios intelectuales, obligatoriamente, debe conducir a también a dotarlos de un tratamiento y de una regulación específica para su contratación por el sector público.

Adicionalmente, se han estudiado las actuaciones preparatorias del contrato de servicios jurídicos aplicando las previsiones contenidas en la LCSP. Y así se han podido constatar, de nuevo, las dificultades que surgen al tratar de reflejar en la documentación preparatoria de la licitación los elementos que conforman el contrato: la determinación concreta del contenido de la asistencia y representación en juicio y su división en lotes; la solvencia técnica versus la confianza; los criterios de adjudicación versus la organización y cualificación del personal; y los procedimientos de licitación previstos por la LCSP para este tipo de servicios. Y dado que la LCSP no regula ninguna especialidad para la contratación de los servicios jurídicos, esta regulación no puede satisfacer las exigencias y particularidades que deben ser consideradas en la contratación de los servicios jurídicos. Los procedimientos previstos en la LCSP están ideados para la contratación de servi- 
REALA. Nueva Época - N.o 11, Abril-Septiembre 2019 - ISSN: 1989-8975 - DOI: 10.24965/reala.v0i11.10570 - [Págs. 184-203]

La contratación de los servicios jurídicos en la ley 9/2017, de 8 de noviembre, de contratos del sector público

Jesús Rubio Beltrán

cios ordinarios y recurrentes del órgano de contratación. Y sólo de considerar los servicios jurídicos como servicios intelectuales sería posible aplicar a su licitación las especialidades previstas por la LCSP, también escasas e insuficientes, para la contratación de los servicios intelectuales.

Esta caracterización de los servicios jurídicos, obligatoriamente, debe conducir a dotarlos de un tratamiento y de una regulación específica para su contratación por el sector público, o bien a su exclusión del ámbito de aplicación de la LCSP, exclusión de la que existen modelos de los que tomar ejemplo en el Derecho comparado europeo.

\section{BIBLIOGRAFÍA}

AGUDO GONZALEZ, J. (2013): "El Fraccionamiento de los Contratos: Invalidez y Fraude de Ley", en Revista de Estudios Locales CUNAL, Número extraordinario.

CASTELLANO, J., RIVERA, R., et al. (2016): Estudio Coste y utilidad de las Diputaciones provinciales: claves para un debate necesario, coordinado por la Fundación ¿Hay Derecho? http://www.ugtdipgra.es/wp-content/ uploads/2016/05/Coste-y-Utilidad_de_las_Diputaciones-2016.pdf (consultado: 15-06-2018).

CASTIÑEIRA PIÑEIRO, J. C. (2018): "Los contratos de servicios en la Ley de Contratos del Sector Público", en Revista de Estudios Locales CUNAL, núm. 205, págs. 318-334.

CHINCHILLA PEINADO, J. A. (2018): "La preparación del contrato", en La nueva Ley de Contratos del Sector Público, págs. 82-115. Ed. lurisutilitas.es.

DÍEZ SASTRE, S. (2017): "Análisis de las novedades en el ámbito de aplicación de la normativa contractual", en Anuario Aragonés de Gobierno Local 2016, págs. 319-358.

Documento de Trabajo de los servicios de la Comisión relativo a la aplicación de la normativa sobre contratación pública de la Unión Europea a las relaciones entre poderes adjudicadores [SEC (2011) 1169, de 4 de octubre de 2011].

GALLEGO CÓRCOLES, I. (2012): Las relaciones "contractuales» entre entes públicos no sometidas a la Directiva 2014/24/UE sobre contratación pública. Trabajo realizado en el marco del Proyecto de investigación concedido por el Ministerio de Economía y Competitividad titulado Hacia una contratación pública eficiente, REF: DER201239003-C02-0. La nueva contratación pública, págs. 111-139.

GARCÍA SÁNCHEZ, I. M., PRADO LORENZO, J. M., CUADRADO BALLESTEROS, B. (2013): "Descentralización y externalización de los servicios municipales: efecto en la eficiencia y calidad de vida", en Formas de Gestión y eficiencia de los servicios públicos municipales, págs. 29-66. Sevilla: Fundación Pública Andaluza. Centro de Estudios Andaluces. Consejería de la Presidencia, Junta de Andalucía.

MESA VILA, M. (2018): "La mutua confianza como fundamento de los contratos de servicios jurídicos, su no tratamiento en el ámbito de la contratación pública", en Revista General de Derecho Administrativo, núm. 47. lustel, enero 2018.

PALOMAR OLMEDA, A. (coord.), GARCES SANAGUSTÍN, M. (coord.) y VAZQUEZ GARRANZO, J. (coord.) (2018): Comentarios a la Ley de Contratos del Sector Público adaptados a la Orden HFP/1298, de 26 de diciembre, págs. 299-374. Wolters Kluwer.

RAZQUIN LIZARRAGA, J. A. (2009): "Las encomiendas a entes instrumentales en la legislación foral de contratos públicos de Navarra: Contraste con el Derecho comunitario europeo y la Legislación Básica Estatal", en Revista Jurídica de Navarra, enero-junio de 2009, núm. 47, págs. 39-86.

SANMARTÍN MORA, M. A. (2018): La contratación de prestaciones de carácter intelectual en la Ley 9/2017 de contratos del sector público. Observatorio de Contratación Pública. http://www.obcp.es/index.php/mod.opiniones/ mem.detalle/id.342/relcategoria.121/relmenu.3/chk.22526a1a262b201d1ee7b78e398eb1e7 (consultado: 15-062018).

SANTIAGO IGLESIAS, D. (2015): "Las relaciones de colaboración entre poderes adjudicadores excluidas de la normativa de contratación del Sector Público: Una Propuesta de transposición de la regulación contenida en las Directivas de Contratación al ordenamiento español”, en Revista General de Derecho Administrativo, núm. 38, lustel, 2015. 